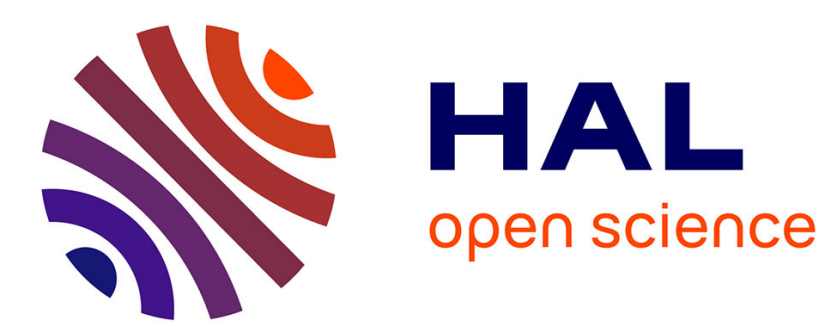

\title{
An Electrochemical Study of Bis(cyclopentadienyl)titanium(IV) Dichloride in the Presence of Magnesium Ions, Amides or Alkynes
}

Abdou Khadre Djily Dimé, Yvan Six, Olivier O. Buriez

\section{- To cite this version:}

Abdou Khadre Djily Dimé, Yvan Six, Olivier O. Buriez. An Electrochemical Study of Bis(cyclopentadienyl)titanium(IV) Dichloride in the Presence of Magnesium Ions, Amides or Alkynes. Elektrokhimiya / Russian Journal of Electrochemistry, 2020, 57 (1), pp.85-91. 10.1134/S1023193521010031 . hal-03081064

\section{HAL Id: hal-03081064 \\ https://hal.science/hal-03081064}

Submitted on 8 Oct 2021

HAL is a multi-disciplinary open access archive for the deposit and dissemination of scientific research documents, whether they are published or not. The documents may come from teaching and research institutions in France or abroad, or from public or private research centers.
L'archive ouverte pluridisciplinaire HAL, est destinée au dépôt et à la diffusion de documents scientifiques de niveau recherche, publiés ou non, émanant des établissements d'enseignement et de recherche français ou étrangers, des laboratoires publics ou privés. 


\title{
An electrochemical study of bis(cyclopentadienyl)titanium(IV) dichloride in the presence of magnesium ions, amide or alkyne derivatives
}

\author{
Abdou K. D. Dimé ${ }^{a, *}$, Yvan Six ${ }^{b}$, and Olivier Buriez ${ }^{c}$ \\ ${ }^{a}$ Equipe Matériaux, Electrochimie et Photochimie Analytiques (EMEPA) de l'Université \\ Alioune Diop de Bambey, B.P. 30 Bambey, Sénégal \\ ${ }^{b}$ Laboratoire de Synthèse Organique (LSO), UMR 7652 CNRS / ENSTA / École \\ Polytechnique, Institut Polytechnique de Paris, 91128 Palaiseau Cedex, France \\ 'PASTEUR, Département de Chimie, Ecole Normale Supérieure, PSL University, Sorbonne \\ Université, CNRS, 75005 Paris, France. \\ *e-mail:abdou.dime@uadb.edu.sn
}

In tetrahydrofuran, the electrochemical reduction of $\mathrm{Cp}_{2} \mathrm{Ti}^{\mathrm{IV}} \mathrm{Cl}_{2}(2 \mathrm{mM})$ generated three titanium(III) complexes which were in equilibrium: $\left[\mathrm{Cp}_{2} \mathrm{TiCl}_{2}\right]^{\bullet-},\left[\mathrm{Cp}_{2} \mathrm{TiCl}\right]^{\bullet}$ and $\left(\mathrm{Cp}_{2} \mathrm{TiCl}\right)_{2}$. Although the anion radical $\left[\mathrm{Cp}_{2} \mathrm{TiCl}_{2}\right]^{--}$was the main species produced under these conditions, cyclic voltammetry investigations clearly showed that the proportion of the three electrogenerated $\mathrm{Ti}^{\mathrm{III}}$ complexes can be modified as a function of the amounts of chloride ion present in the solution. Accordingly, the presence of $\mathrm{Mg}^{2+}$ ions, which led to the consumption of chloride ions through the formation of $\mathrm{MgCl}_{2}$, favoured the formation of $\left[\mathrm{Cp}_{2} \mathrm{TiCl}\right]^{\bullet}$ and, consequently, of the corresponding dimer $\left(\mathrm{Cp}_{2} \mathrm{TiCl}\right)_{2}$. The electrochemical behaviours of $\mathrm{Cp}_{2} \mathrm{Ti}^{\mathrm{IV}} \mathrm{Cl}_{2}$ and of the electrogenerated low-valent $\mathrm{Ti}$ complexes were also investigated in the presence of amide and alkyne derivatives. Under these conditions, titanium complexes could not only interact with the amide carbonyl group, but also with the alkyne triple bond, provided the latter was not sterically hindered. Interestingly, the carbonyl group and the triple bond had antagonist effects on redox properties of titanium(III) complexes.

Keywords: Titanium, titanocene, cyclic voltammetry, amide, alkyne. 


\section{INTRODUCTION}

In recent years, there has been a revival in the chemistry of bis(cyclopentadienyl)titanium chloride $\left(\mathrm{Cp}_{2} \mathrm{Ti}^{\mathrm{III}} \mathrm{Cl}\right)$, especially in the field of radical organic synthesis [1-4]. Indeed, the use of this organometallic complex, obtained by the monoelectronic reduction of $\mathrm{Cp}_{2} \mathrm{Ti}^{\mathrm{IV}} \mathrm{Cl}_{2}$ and which possesses an unpaired electron on its metal center, has become a powerful tool not only in reactions involving electron transfer processes such as epoxide openings [5,6], but also in pinacol coupling reactions [7,8], in Reformatsky-type reactions [9], and in other transformations involving polarity reversal [10-14]. Furthermore, the development of catalytic protocols allowing the regeneration of the $\mathrm{Cp}_{2} \mathrm{Ti}^{\mathrm{IV}} \mathrm{Cl}_{2}$ starting complex after single electron transfer has significantly contributed to increasing the popularity of $\mathrm{Cp}_{2} \mathrm{Ti}^{\mathrm{III}} \mathrm{Cl}$ [15-18]. The preparation of this complex can be easily achieved by the reduction of $\mathrm{Cp}_{2} \mathrm{Ti}^{\mathrm{IV}} \mathrm{Cl}_{2}$ in the presence of suitable metals (e.g. zinc [19], aluminium [20] or manganese [21]), although this procedure also generates metal cations in solution. To overcome this drawback, the electrochemical reduction of $\mathrm{Cp}_{2} \mathrm{Ti}^{\mathrm{IV}} \mathrm{Cl}_{2}$ appeared as an efficient alternative strategy. In both cases, the work reported by Daasbjerg et al. has highlighted the mechanistic aspects of the chemical or electrochemical reduction of $\mathrm{Cp}_{2} \mathrm{Ti}^{\mathrm{IV}} \mathrm{Cl}_{2}$ [23-25]. Based on cyclic voltammetry investigations, it was clearly demonstrated that the electrochemical reduction of the $\mathrm{Ti}^{\mathrm{IV}}$ complex mainly leads to the formation of the anion radical $\left[\mathrm{Cp}_{2} \mathrm{TiCl}_{2}\right]^{\bullet-}$, whereas its chemical reduction by metals $(\mathrm{Zn}, \mathrm{Al}, \mathrm{Mn})$ leads to an equilibrium mixture of the radical $\left[\mathrm{Cp}_{2} \mathrm{TiCl}\right]^{\bullet}$ and the corresponding dimer $\left[\mathrm{Cp}_{2} \mathrm{TiCl}\right]_{2}$. In the latter case, and independently of the nature of the reducing metal, the dimerization equilibrium constant was found equal to $3.10^{3} \mathrm{M}^{-1}$ [25]. It was also found that the reactivity of $\mathrm{Ti}^{\mathrm{III}}$ complexes, which is strongly dependent on both the nature of the substrate and the experimental conditions, is difficult to predict. For instance, the dimer $\left[\mathrm{Cp}_{2} \mathrm{TiCl}\right]_{2}$ has been judged as poorly reactive towards ketones or aliphatic aldehydes [26]. Nevertheless, Cuerva and Oltra showed that acetophenone may undergo a pinacol coupling reaction in the presence of $\left[\mathrm{Cp}_{2} \mathrm{TiCl}\right]_{2}$, provided that the metals used for the reduction (Mn or $\mathrm{Zn}$ ) are employed in excess amounts [27]. Surprisingly, it was also shown that $\left[\mathrm{Cp}_{2} \mathrm{TiCl}\right]_{2}$ was the most reactive species towards benzaldehyde, compared to $\left[\mathrm{Cp}_{2} \mathrm{TiCl}_{2}\right]^{\bullet-}$ or $\left[\mathrm{Cp}_{2} \mathrm{TiCl}\right]^{\bullet}$.

Taking into account the current resurgence in the use of $\mathrm{Ti}^{\mathrm{III}}$ species, we decided to explore their behaviours under experimental conditions that are typically applied in radical organic synthesis. Within this context, it was notably important to investigate how metal cations may impact the equilibrium between the $\mathrm{Ti}^{\mathrm{III}}$ complexes generated by monoelectronic reduction of 
$\mathrm{Cp}_{2} \mathrm{Ti}^{\mathrm{IV}} \mathrm{Cl}_{2}$. Moreover, it was relevant to study the behaviours of the $\mathrm{Ti}^{\mathrm{III}}$ complexes in the presence of important classes of organic compounds such as amide and alkyne derivatives, because the presence of a carbonyl group or of a triple bond may lead to specific interaction/complexation with the titanium metal center. This work was performed by cyclic voltammetry, a powerful analytical technique that is particularly suitable for this kind of exploration [28].

\section{EXPERIMENTAL}

\section{Reagents}

Tetrahydrofuran (THF, Carlo-Erba RPE quality), was distilled, under argon, over sodium and benzophenone. Tetrabutylammonium tetrafluoroborate $\left(\mathrm{TBABF}_{4}\right)$ was used as the supporting electrolyte for the electrochemical investigations; it was prepared from $\mathrm{NaBF}_{4}$ (Acros) and $n \mathrm{Bu}_{4} \mathrm{NHSO}_{4}$ (Acros), then recrystallised from EtOAc/hexane (both Acros) and dried at $60{ }^{\circ} \mathrm{C}$. Diphenylacetylene (Acros, purity 99\%), phenylacetylene (Acros, purity 98\%) and magnesium perchlorate (Acros) were used as received. $\mathrm{N}$-but-3-enyl- $\mathrm{N}$-(4-methoxyphenyl)acetamide (BMA) was synthesized as described elsewhere [29].

\section{Instrumentation}

All electrochemical manipulations were performed using Schlenk techniques in an atmosphere of dry oxygen-free argon, at room temperature. The supporting electrolyte was degassed under vacuum before use and then dissolved to a concentration of $0.3 \mathrm{~mol} / \mathrm{L}$. Voltammetric analyses were carried out in a standard three-electrode cell, with an Autolab PGSTAT $302 \mathrm{~N}$ potentiostat, connected to an interfaced computer installed with the Electrochemistry Nova software. The reference electrode was a saturated calomel electrode (SCE) separated from the analysed solution by a sintered glass disk filled with the background solution. The auxiliary electrode was a platinum wire separated from the analysed solution by a sintered glass disk filled with the background solution. For all voltammetric measurements, the working electrode was a glassy carbon electrode $(\varnothing=1 \mathrm{~mm}$, Goodfellow). 


\section{RESULTS AND DISCUSSION}

\section{Electrochemical behaviour of $\mathrm{Cp}_{2} \mathrm{Ti}^{I V} \mathrm{Cl}_{2}$ in the absence and in the presence of magnesium}

salts

The first part of the work was aimed at evidencing a possible impact of metal cations on the equilibrium involving $\mathrm{Ti}^{\mathrm{III}}$ complexes obtained after the monoelectronic reduction of $\mathrm{Cp}_{2} \mathrm{Ti}^{\mathrm{IV}} \mathrm{Cl}_{2}$. Typically, since titanium complexes are sometimes associated with Grignard reagents [30-32], it was relevant to investigate whether the presence of magnesium ions is prone to affect the $\mathrm{Ti}^{\mathrm{III}}$ complexes repartition displayed in Scheme 1.

In this work, both the reduction of $\mathrm{Cp}_{2} \mathrm{Ti}^{\mathrm{IV}} \mathrm{Cl}_{2}$ and the analysis of the corresponding generated $\mathrm{Ti}^{\mathrm{III}}$ complexes were performed by cyclic voltammetry. As shown in Figure 1, the cyclic voltammogram $(\mathrm{CV})$ of $\mathrm{Cp}_{2} \mathrm{Ti}^{\mathrm{IV}} \mathrm{Cl}_{2}$, obtained in $\mathrm{THF}$ with $0.3 \mathrm{M} \mathrm{TBABF}_{4}$ as supporting electrolyte, exhibited a first fully reversible reduction process (noted as $\mathrm{O}_{1} / \mathrm{R}_{1} ; \mathrm{E}^{\circ}=\left(\mathrm{E}_{\mathrm{pa}}+\right.$ $\left.\left.E_{p c}\right) / 2=-0.74 \mathrm{~V}\right)$ followed by a pseudo-reversible system $\left(E_{R 2}=-2.08 \mathrm{~V}\right)$. The reversibility of R2 was more or less clearly visible, depending on how well the electrode surface had been polished.

As described by K. Daasbjerg et al. [24], the first process $\mathrm{R}_{1} / \mathrm{O}_{1}$ involves a relatively complex mechanism despite its apparent neat reversibility. Actually, and as illustrated in Scheme 1, the mono-electronic reduction of $\mathrm{Cp}_{2} \mathrm{TiCl}_{2}$ initially produces the corresponding radical anion species. At low scan rates $(v<0.5 \mathrm{~V} / \mathrm{s})$, the latter has enough time to dissociate and generate the radical $\left[\mathrm{Cp}_{2} \mathrm{TiCl}\right]^{\bullet}$ while releasing a chloride anion. Under these conditions, the radical species $\left[\mathrm{Cp}_{2} \mathrm{TiCl}\right]^{\bullet}$ was shown to be in equilibrium with the corresponding dimer $\left(\mathrm{Cp}_{2} \mathrm{TiCl}\right)_{2}$. Based on simulated voltammograms, K. Daasbjerg et al. could even determine the equilibrium constants involved between these three complexes (Scheme 1) [24]. From these constants, it was notably established that the electrochemical reduction of a $2 \mathrm{mM} \mathrm{C} \mathrm{Cp}_{2} \mathrm{TiCl}_{2}$ solution (conditions used in this work) generated the anion radical $\left[\mathrm{Cp}_{2} \mathrm{TiCl}_{2}\right]^{--}$as the major species $(1.35 \mathrm{mM})$, whereas both the radical $\left[\mathrm{Cp}_{2} \mathrm{TiCl}\right]^{\bullet}$ and the dimer $\left(\mathrm{Cp}_{2} \mathrm{TiCl}\right)_{2}$ species were present at lower concentrations ( 0.21 and $0.22 \mathrm{mM}$, respectively).

Although the electrochemical reduction of $\mathrm{Cp}_{2} \mathrm{TiCl}_{2}$ generates three different complexes, the $\mathrm{CV}$ in Figure 1 revealed only one oxidation wave when the potential sweep was inverted after $\mathrm{R}_{1}$. This is due to the fact that cyclic voltammetry is a dynamic technique, with the three complexes resulting from the reduction of $\mathrm{Cp}_{2} \mathrm{TiCl}_{2}$ being in equilibrium. In other words, the second-order back association reaction between $\left[\mathrm{Cp}_{2} \mathrm{TiCl}\right]^{\bullet}$ and $\mathrm{Cl}^{-}$is fast enough to leave $\left[\mathrm{Cp}_{2} \mathrm{TiCl}_{2}\right]^{\bullet-}$ as the only species detectable on the reverse sweep (Scheme 1). This process, 
that is all the more efficient that the scan rate is low (i.e., that the timescale becomes longer) therefore generates only one wave $\left(\mathrm{O}_{1}\right)$ corresponding to the oxidation of the anion radical.

Accordingly, the reduction wave $\mathrm{R}_{2}$ observed in Figure $1\left(\mathrm{E}_{\mathrm{R} 2}=-2.08 \mathrm{~V}\right)$ can be assigned to the reduction of either the radical $\left[\mathrm{Cp}_{2} \mathrm{TiCl}\right]^{\bullet}$ or the dimer $\left(\mathrm{Cp}_{2} \mathrm{TiCl}\right)_{2}$.

Under otherwise identical conditions, how is the $\mathrm{CV}$ of $\mathrm{Cp}_{2} \mathrm{TiCl}_{2}$ modified in the presence of magnesium ions? In Figure 2 is shown a typical $\mathrm{CV}$ of the titanium(IV) complex recorded in the presence of one molar equivalent of $\mathrm{Mg}^{2+}$ added in solution in the form of $\mathrm{Mg}\left(\mathrm{ClO}_{4}\right)_{2}$.

Clearly, several changes can be observed compared to the CV obtained in the absence of magnesium salts. First, the reduction wave $R_{1}$ was slightly shifted towards a less negative potential value $\left(\mathrm{E}_{\mathrm{R}}{ }^{\prime} 1=-0.73 \mathrm{~V}\right.$ vs. $\left.\mathrm{E}_{\mathrm{R} 1}=-0.79 \mathrm{~V}\right)$, indicating the presence of a new chemical reaction following the electron transfer, that would facilitate the electrogenerated anion radical dissociation. Within the same long time-scale $(v=0.1 \mathrm{~V} / \mathrm{s})$, the oxidation wave $\mathrm{O}_{1}$ corresponding to the oxidation of the anion radical $\left[\mathrm{Cp}_{2} \mathrm{TiCl}_{2}\right]^{\bullet-}$ is split into two new oxidation waves, noted as $\mathrm{O}_{3}$ and $\mathrm{O}_{4}$ and located at $\mathrm{E}_{\mathrm{O} 3}=-0.56 \mathrm{~V}$ and $\mathrm{E}_{\mathrm{O} 4}=-0.41 \mathrm{~V}$, respectively. Indeed, under these conditions, the anion radical does not exist anymore in the diffusion layer. By analogy with the work reported by K. Daasbjerg and coworkers, $\mathrm{O}_{3}$ and $\mathrm{O}_{4}$ can be assigned to the oxidation of the dimer $\left(\mathrm{Cp}_{2} \mathrm{TiCl}\right)_{2}$ and of the radical $\left[\mathrm{Cp}_{2} \mathrm{TiCl}\right]^{\bullet}$ species, respectively.

In summary, this behaviour clearly indicates that the complexation between $\mathrm{Mg}^{2+}$ and $\mathrm{Cl}^{-}$ displaces the equilibrium shown in Scheme 1 towards the production of $\left[\mathrm{Cp}_{2} \mathrm{TiCl}\right]^{\bullet}$. Moreover, these findings can be compared to those obtained when $\mathrm{Cp}_{2} \mathrm{TiCl}_{2}$ is chemically reduced by a metal such as zinc $[19,27]$. In other words, the $\mathrm{Mg}^{2+}$ ions added under electrochemical conditions play a similar role to the $\mathrm{Zn}^{2+}$ ions generated during the chemical reduction of $\mathrm{Cp}_{2} \mathrm{TiCl}_{2}$ by $\mathrm{Zn}$.

It is also worthy of note that the addition of magnesium salts in the $\mathrm{Cp}_{2} \mathrm{TiCl}_{2}$ solution leads to a peak current increase of $\mathrm{R}_{2}$ (Figure 2). This reveals that the concentration of the species reduced at this potential value (i.e., $\left[\mathrm{Cp}_{2} \mathrm{TiCl}\right]^{\bullet}$ or $\left.\left(\mathrm{Cp}_{2} \mathrm{TiCl}\right)_{2}\right)$ increase in the diffusion layer. This is consistent with the interpretation described above; however, it is difficult at this stage to draw unambiguous conclusions about the exact nature of the $\mathrm{Ti}^{\mathrm{III}}$ species that is reduced at the level of $R_{2}$. 
Electrochemical behaviour of $\mathrm{Cp}_{2} \mathrm{Ti}^{I V} \mathrm{Cl}_{2}$ in the absence and in the presence of amide or alkyne derivatives

In the previous part, we demonstrated that equilibria involving titanium(III) complexes can be displaced by reducing the concentration of free chloride ions in solution. Another objective of this work was also to obtain qualitative information on possible complexation of low-valent titanium complexes with important organic substrates such as $N$-but-3-enylamides and alkyne derivatives. Indeed, these compounds can be chemically transformed into high added value compounds such as aminocyclopropanes and Z-alkenes, respectively. However, these processes involve the presence of titanium(II) complexes, generated under drastically different conditions i.e., from $\mathrm{Ti}(\mathrm{O} i \mathrm{Pr})_{4}$ associated with a polar organometallic compound such as a Grignard reagent [32-35] or, more rarely, an organolithium compound [36-37].

In the presence of $N$-but-3-enyl-N-(4-methoxyphenyl)acetamide (BMA)

The electrochemical behaviour of $\mathrm{Cp}_{2} \mathrm{TiCl}_{2}$ was first investigated in the presence of BMA, a substrate that proved to be useful for the preparation of endoperoxides having antimalarial activity [29]. As shown in Figure 3(a), the peak current intensities of both $\mathrm{R}_{1}$ and $\mathrm{O}_{1}$ concomitantly decreased as the BMA concentration increased. Under the same conditions, the wave $\mathrm{R}_{2}$ shifted towards more negative potential values (Figure 3(b)).

These behaviours are very likely related to a complexation occurring between the Ti metal center and the carbonyl group of BMA, in agreement with the Lewis acidity and oxophilic properties of titanium. Such a complexation between the starting complex and BMA would therefore lead to " $\mathrm{Cp}_{2} \mathrm{TiCl}_{2}$-amide" complex having a lower diffusion coefficient than $\mathrm{Cp}_{2} \mathrm{TiCl}_{2}$ in agreement with a decrease of both $\mathrm{I}\left(\mathrm{R}_{1}\right)$ and $\mathrm{I}\left(\mathrm{O}_{1}\right)$.

Moreover, a complexation would also occur between BMA and electrogenerated $\mathrm{Ti}^{\mathrm{III}}$ complexes (in $\mathrm{R}_{1}$ ) before reduction of the latter (in $\mathrm{R}_{2}$ ), in agreement with the potential shift of $\mathrm{R}_{2}$ towards more negative potential values (Figure 3(b)). In other words, the complexation between the BMA carbonyl electron-donating group and the $\mathrm{Ti}^{\mathrm{III}}$ metal center made the complex reduction more difficult.

\section{In the presence of alkyne derivatives}

Even more than $\mathrm{N}$-but-3-enyl amide compounds, alkyne derivatives are substrates of high importance in organic synthesis because their reduction gives access to alkene products. The electrochemical behaviour of $\mathrm{Cp}_{2} \mathrm{TiCl}_{2}$ was comparable in the absence and in the presence of one molar equivalent of diphenylacetylene (Figure 4). The same voltammograms were also 
obtained when diphenylacetylene was used in excess (not shown). These results clearly demonstrate the absence of complexation between diphenylacetylene and titanium complexes $\left(\mathrm{Ti}^{\mathrm{IV}}\right.$ and $\left.\mathrm{Ti}^{\mathrm{III}}\right)$. This also confirms the important role of the carbonyl group in the complexation reaction occurring between the titanium metal center and the amide derivative BMA (previous paragraph).

It was hypothesised that the absence of changes in the CVs shown in Figure 4 could be due to the steric hindrance of the triple bond (presence of one aromatic ring at each side of the triple bond) which would prevent an easy access to the titanium complex. Phenylacetylene was therefore investigated instead of diphenylacetylene. Contrary to what had been observed previously with BMA, no changes were observed on the $\mathrm{R}_{1} / \mathrm{O}_{1}$ system even in the presence of phenylacetylene used in excess (20 molar equivalents, not shown). However, in the presence of increasing amounts of phenylacetylene, the wave $\mathrm{R}_{2}$ shifted towards less negative potential values, while the process remained reversible (Figure 5). Contrarily to the situation observed with BMA, the reduction process occurring in $\mathrm{R}_{2}$ became therefore easier (negative $v s$. positive shift of the potential wave $\mathrm{R}_{2}$ ). This experimental observation is consistent with a complexation between the electrogenerated $\mathrm{Ti}^{\mathrm{II}}$ complex and the triple bond, which thus facilitates the reduction of $\mathrm{Ti}^{\mathrm{III}}$ (EC-type mechanism).

\section{CONCLUSION}

This work was aimed at using cyclic voltammetry to explore the behaviour of the reduced titanium species under the experimental conditions that are typically applied when $\mathrm{Cp}_{2} \mathrm{TiCl}_{2}$ is used in radical organic synthesis. Interestingly, it was clearly shown that the presence of metal salts that are able to subtract chloride ions freely diffusing in solution impacts the ratio of the $\mathrm{Ti}^{\mathrm{III}}$ complexes generated by monoelectronic reduction of $\mathrm{Cp}_{2} \mathrm{Ti}^{\mathrm{IV}} \mathrm{Cl}_{2}$. Typically, a decrease of the $\mathrm{Cl}^{-}$concentration (via the addition of $\mathrm{Mg}^{2+}$ to produce $\mathrm{MgCl}_{2}$ ) favoured the formation of $\left[\mathrm{Cp}_{2} \mathrm{TiCl}\right]^{\bullet}$ and, consequently, of the corresponding dimer $\left[\mathrm{Cp}_{2} \mathrm{TiCl}\right]_{2}$. Importantly, this behaviour mimics the situation observed under classic conditions involving reducing metals ( $\mathrm{Zn}, \mathrm{Mn}$ and $\mathrm{Al}$ ), where metal chloride salts are produced. Furthermore, it was shown that organic compounds bearing either a carbonyl group or a non-sterically hindered triple bond may have antagonist effects on redox properties of titanium(III) complexes. Accordingly, the complexation between the BMA carbonyl electron-donating group and the $\mathrm{Ti}^{\mathrm{III}}$ metal center made the complex reduction more difficult. Conversely, the reduction of the $\mathrm{Ti}^{\mathrm{III}}$ species was 
facilitated in the presence of phenylacetylene because of complexation between the $\mathrm{Ti}^{\mathrm{II}}$ thus produced and the alkyne triple bond.

\section{CONFLICT OF INTERESTS}

The authors state that they have no conflict of interests.

\section{FUNDING}

This work was supported by the Agence Nationale de la Recherche (grant number: ANR-12BS07-0013 “ACTIMAC”), the Centre National de la Recherche Scientifique (CNRS), the École Normale Supérieure, École Polytechnique and Sorbonne University. 


\section{REFERENCES}

1. Rosales, A., Rodríguez-García, I., Muñoz-Bascón, J., Roldan-Molina, E., Padial, N.M., Morales, L.P., García-Ocaña, M., and Oltra, J.E., The nugent reagent: a formidable tool in contemporary radical and organometallic chemistry, Eur. J. Org. Chem., 2015, vol. 21, p. 4567.

2. Gansäuer, A., and Bluhm, H., Reagent-controlled transition-metal-catalyzed radical reactions, Chem. Rev., 2000, vol. 100, p. 2771.

3. Cuerva, J.M., Justicia, J., Oller-López, J.L., and Oltra, J.E., $\mathrm{Cp}_{2} \mathrm{TiCl}$ in natural product synthesis, Top. Curr. Chem., 2006, vol. 264, p. 63.

4. Streuff, J., The electron-way: metal-catalyzed reductive umpolung reactions of saturated and $\alpha, \beta$-unsaturated carbonyl derivatives, Synthesis, 2013, vol. 45, p. 281.

5. RajanBabu, T.V., and Nugent, W.A., Selective generation of free radicals from epoxides using a transition-metal radical. A powerful new tool for organic synthesis, $J$. Am. Chem. Soc., 1994, vol.116, p. 986.

6. Gansäuer, A., Bluhm, H., and Pierobon, M., Emergence of a novel catalytic radical reaction: titanocene-catalyzed reductive opening of epoxides, J. Am. Chem. Soc., 1998, vol. 120, p. 12849.

7. Gansäuer, A., Novel concept for efficient transition-metal-catalyzed reactions: a highly diastereoselective titanocene-catalyzed pinacol coupling under buffered protic conditions, J. Org. Chem., 1998, vol. 63, p. 2070.

8. Gansäuer, A., and Bauer, D., A novel concept for transition-metal-catalyzed reactions: electron transfer under buffered protic conditions, Eur. J. Org. Chem., 1998, vol. 11, p. 2673.

9. Estévez, R.E., Paradas, M., Millán, A., Jiménez, T., Robles, R., Cuerva, J.M., and Oltra, J.E., Ti-catalyzed Reformatsky-type coupling between $\alpha$-halo ketones and aldehydes, $J$. Org. Chem., 2008, vol. 73, p. 1616.

10. Estévez, R.F., Oller-López, J.L., Robles, R., Melgarejo, C.R., Gansäuer, A., Cuerva, J.M., and Oltra, J.E., Stereocontrolled coupling between aldehydes and conjugated alkenals mediated by $\mathrm{Ti}^{\mathrm{iII}} / \mathrm{H}_{2} \mathrm{O}$, Org. Lett., 2006, vol. 8, p. 5433. 
11. Streuff, J., A titanium(III)-catalyzed redox umpolung reaction for the reductive crosscoupling of enones with acrylonitriles, Chem. Eur. J., 2011, vol. 17, p. 5507.

12. Feurer, M., Frey, G., Luu, H.-T., Kratzert, D., and Streuff, J., The cross-selective titanium(III)-catalysed acyloin reaction, Chem. Commun., 2014, vol. 50, p. 5370.

13. Frey, G., Luu, H.-T., Bichovski, P., Feurer, M., and Streuff, J., Convenient titanium(III)-catalyzed synthesis of cyclic aminoketones and pyrrolidinonesdevelopment of a formal [4+1] cycloaddition, Angew. Chem. Int. Ed., 2013, vol. 52, p. 7131; Praktische titan(III)-katalysierte synthese von cyclischen aminoketonen und pyrrolidinonen - entwicklung einer formalen [4+1]-cycloaddition, Angew. Chem., 2013, vol. 125, p. 7271.

14. Bichovski, P., Haas, T.M., Kellera, M., and Streuff, J., Direct conjugate alkylation of $\alpha, \beta-$ unsaturated carbonyls by $\mathrm{Ti}^{\mathrm{III}}$-catalysed reductive umpolung of simple activated alkenes, Org. Biomol. Chem., 2016, vol. 14, p. 5673.

15. Zhang, Y., and Liu, T., $\mathrm{Cp}_{2} \mathrm{TiCl}_{2}$-catalyzed reaction of Grignard reagents with diaryl ketones, formation of pinacolic coupling from diaryl ketones, Synth. Commun., 1988, vol. 18, p. 2173.

16. Gansäuer, A., Pierobon, M., and Bluhm, H., Catalytic, highly regio- and chemoselective generation of radicals from epoxides: titanocene dichloride as an electron transfer catalyst in transition metal catalyzed radical reactions, Angew. Chem. Int. Ed., 1998, vol. 37, p. 101; Catalytic, highly regio- and chemoselective generation of radicals from epoxides: titanocenes as electron transfer catalysts in transition metal catalyzed radical reactions, Angew. Chem., 1998, vol. 110, p. 107.

17. Barrero, A.F., Rosales, A., Cuerva, J.M., and Oltra, J.E., Unified synthesis of eudesmanolides, combining biomimetic strategies with homogeneous catalysis and freeradical chemistry, Org. Lett. 2003, vol. 5, p. 1935.

18. Fuse, S., Hanochi, M., Doi, T., and Takahashi, T., Ti(III)-catalyzed radical cyclization of 6,7-epoxygeranyl acetate, Tetrahedron Lett., 2004, vol. 45, p. 1961.

19. Coutts, R.S.P., Wailes, P.C., and Martin, R.L., Novel reactions of monocyclopentadienyltitanium(III) dihalides with organic carbonyl groups, $J$. Organomet. Chem., 1973, vol. 50, p. 145.

20. Birmingham, J.M., Fischer, A.K., and Wilkinson, G., The reduction of biscyclopentadienyl compounds, Naturwissenschaften, 1955, vol. 42, p. 96.

21. Sekutowski, D.J., and Stucky, G.D., Synthesis and structure of some bis(cyclopentadienyl)titanium(III) metal halides, Inorg. Chem., 1975, vol. 14, p. 2192. 
22. Samuel, E., and Vedel, J., Electrochemical and chemical reduction of titanocene dihalides - an ESR study, Organometallics, 1989, vol. 8, p. 237.

23. Enemærke, R.J., Hjøllund, G.H., Daasbjerg, K., and Skrydstrup, T., Is the trinuclear complex the true reducing species in the $\mathrm{Cp}_{2} \mathrm{TiCl}_{2} / \mathrm{Mn}$-and $\mathrm{Cp}_{2} \mathrm{TiCl}_{2} / \mathrm{Zn}$-promoted pinacol coupling? C. R. Acad. Sci. Ser. IIc: Chim., 2001, vol. 4, p. 435.

24. Enemærke, R.J., Larsen, J., Skrydstrup, T., and Daasbjerg, K., Mechanistic investigation of the electrochemical reduction of $\mathrm{Cp}_{2} \mathrm{TiX}_{2}$, Organometallics, 2004, vol. 23, p. 1866.

25. Enemærke, R.J., Larsen, J., Skrydstrup, T., and Daasbjerg, K., Revelation of the nature of the reducing species in titanocene halide-promoted reductions, J. Am. Chem. Soc., 2004, vol. 126, p. 7853.

26. Barden, M.C., and Schwartz, J., Stereoselective pinacol coupling in aqueous media, $J$. Am. Chem. Soc., 1996, vol. 118, p. 5484.

27. Paradas, M., Campaña, A.G., Estévez, R.E., Álvarez de Cienfuegos, L., Jiménez, T., Robles, R., Cuerva, J.M., and Oltra, J.E., Unexpected Ti ${ }^{\mathrm{III}} / \mathrm{Mn}$-promoted pinacol coupling of ketones, J. Org. Chem., 2009, vol. 74, p. 3616.

28. Labbé, E., and Buriez, O., The fundamental input of analytical electrochemistry in the determination of intermediates and reaction mechanisms in electrosynthetic processes, ChemElectroChem, 2019, vol. 6, p. 4118.

29. Madelaine, C., Buriez, O., Crousse, B., Florent, I., Grellier, P., Retailleau, P., and Six, Y., Aminocyclopropanes as precursors of endoperoxides with antimalarial activity, Org. Biomol. Chem., 2010, vol. 8, p. 5591.

30. Kulinkovich, O.G., Sviridov, S.V., Vasilevskii, D.A., and Prityskaya, T.S., Reaction of ethylmagnesium bromide with carboxylic esters in the presence of tetraisopropoxytitanium, Russ. J. Org. Chem., 1989, vol. 25, p. 2027.

31. Kulinkovich, O.G., Sviridov, S.V., and Vasilevski, D.A., Titanium(IV) isopropoxidecatalyzed formation of 1-substituted cyclopropanols in the reaction of ethylmagnesium bromide with methyl alkanecarboxylates, Synthesis, 1991, p. 234.

32. a) Wolan, A., and Six, Y., Synthetic transformations mediated by the combination of titanium(IV) alkoxides and Grignard reagents: selectivity issues and recent applications. Part 1: reactions of carbonyl derivatives and nitriles, Tetrahedron, 2010, vol. 66, p. 15; b) Wolan, A., and Six, Y., Synthetic transformations mediated by the combination of titanium(IV) alkoxides and Grignard reagents: selectivity issues and recent applications. Part 2: Reactions of alkenes, allenes and alkynes, Tetrahedron, 2010, vol. 66, p. 3097; 
c) Cha J.K., and Kulinkovich, O.G., The Kulinkovich cyclopropanation of carboxylic acid derivatives, In Organic Reactions, Ed. S. E. Denmark: John Wiley \& Sons, 2012, p. 17. d) Ebner, C., and Carreira, E.M., Cyclopropanation strategies in recent total syntheses, Chem. Rev., 2017, vol. 117, p. 11651.

33. Chaplinski, V., and de Meijere, A., A versatile new preparation of cyclopropylamines from acid dialkylamides, Angew. Chem. Int. Ed., 1996, vol. 35, p. 413.

34. Lee, J., and Cha, J.K., Facile preparation of cyclopropylamines from carboxamides, J. Org. Chem., 1997, vol. 62, p. 1584.

35. a) de Meijere, A., Chaplinski, V., Winsel, H., Kordes, M., Stecker, B., Gazizova, V., Savchenko, A. I., Boese, R., and Schill F., (born Brackmann), Cyclopropylamines from N,N-dialkylcarboxamides and Grignard reagents in the presence of titanium tetraisopropoxide or methyltitanium triisopropoxide, Chem. Eur. J., 2010, vol. 16, p. 13862.

36. a) Rassadin, V.A., and Six, Y., A study of the reaction of $n B u L i$ with $\mathrm{Ti}(\mathrm{OiPr})_{4}$ as a method to generate titanacyclopropane and titanacyclopropene species, Tetrahedron, 2014, vol. 70, p. 787; b) Rosenthal, U., Pellny, P-M.; Kirchbauer, F.G.; Burlakov, V.V., What do titano- and zirconocenes do with diynes and polyynes?, Chem. Rev., 2000, vol. 33 , p. 119; c) Rosenthal, U., Burlakov, V.V., Arndt, P.; Baumann, W., Spannenberg, A., The titanocene complex of bis(trimethylsilyl)acetylene: synthesis, structure, and chemistry, Organometallics, 2003, vol. 22 , p. 884.

37. a) Mizoguchi, H., and Micalizio, G.C., Synthesis of highly functionalized decalins via metallacycle-mediated Cross-coupling, J. Am. Chem. Soc., 2015, vol. 137, p. 6624; b) Mizoguchi, H., and Micalizio, G.C., Synthesis of angularly substituted trans-fused decalins through a metallacycle-mediated annulative Cross-coupling cascade, Angew. Chem. Int. Ed., 2016, vol. 55, p. 13099; c) Kim, W.S., Du, K., Hughes, R.P., and Micalizio, G.C., Synthetic nat- or ent-steroids in as few as five chemical steps from epichlorohydrin, Nature Chem., 2018, vol. 10, p. 70; d) Shalit, Z.A., and Micalizio, G.C., A highly chemo-, regio-, and stereoselective metallacycle-mediated annulation between a conjugated enyne and an ene-diyne, arkivoc, 2018, vol. 4, p. 132. 


\section{SCHEME CAPTIONS}

Scheme 1: Main $\mathrm{Ti}^{\mathrm{III}}$ complexes involved after the electrochemical reduction of $\mathrm{Cp}_{2} \mathrm{TiCl}_{2}$ in THF (transformations put under scrutiny in this work are displayed in blue) [24].

\section{FIGURE CAPTIONS}

Figure 1: Cyclic voltammogram of $\mathrm{Cp}_{2} \mathrm{TiCl}_{2}\left(2.10^{-3} \mathrm{M}\right)$ in $\mathrm{THF} / n \mathrm{Bu}_{4} \mathrm{NBF}_{4}(0.3 \mathrm{M})$ at a glassy carbon working electrode $(\varnothing=1 \mathrm{~mm})$ and at $v=100 \mathrm{mV} / \mathrm{s}$.

Figure 2: $\quad$ Cyclic voltammograms of $\mathrm{Cp}_{2} \mathrm{TiCl}_{2}\left(2.10^{-3} \mathrm{M}\right)$ in THF / $n \mathrm{Bu}_{4} \mathrm{NBF}_{4}(0.3 \mathrm{M})$ in the absence (solid line) and in the presence (dashed line) of $\mathrm{Mg}\left(\mathrm{ClO}_{4}\right)_{2}\left(2.10^{-3}\right.$ M). CVs obtained at a glassy carbon working electrode $(\varnothing=1 \mathrm{~mm})$ and at $v=$ $100 \mathrm{mV} / \mathrm{s}$.

Figure 3a: Cyclic voltammograms of $\mathrm{Cp}_{2} \mathrm{TiCl}_{2}\left(2.10^{-3} \mathrm{M}\right)$ recorded in $\mathrm{THF} / n \mathrm{Bu}_{4} \mathrm{NBF}_{4}$ $(0.3 \mathrm{M})$, at a glassy carbon electrode $(1 \mathrm{~mm}$ in diameter), in the absence (solid lines) and in the presence of BMA: $2.10^{-3} \mathrm{M}$ (dashed lines); $20.10^{-3} \mathrm{M}$ (dotted lines); $40.10^{-3} \mathrm{M}$ (dash dotted lines). The potential sweep was inverted at $-1 \mathrm{~V}$.

Figure 3b: Cyclic voltammograms of $\mathrm{Cp}_{2} \mathrm{TiCl}_{2}\left(2.10^{-3} \mathrm{M}\right)$ recorded in $\mathrm{THF} / n \mathrm{Bu}_{4} \mathrm{NBF}_{4}$ $(0.3 \mathrm{M})$, at a glassy carbon electrode $(1 \mathrm{~mm}$ in diameter), in the absence (solid lines) and in the presence of BMA: $2.10^{-3} \mathrm{M}$ (dashed lines); $20.10^{-3} \mathrm{M}$ (dotted lines); $40.10^{-3} \mathrm{M}$ (dash dotted lines). The potential sweep was inverted at -2.2 V.

Figure 4: Cyclic voltammograms of $\mathrm{Cp}_{2} \mathrm{TiCl}_{2}\left(2.10^{-3} \mathrm{M}\right)$ in $\mathrm{THF} / n \mathrm{Bu}_{4} \mathrm{NBF}_{4}(0.3 \mathrm{M})$, at a glassy carbon electrode ( $1 \mathrm{~mm}$ in diameter), in the absence (solid line) and in the presence (dashed line) of diphenylacetylene $\left(2.10^{-3} \mathrm{M}\right)$. Scan rate: 50 $\mathrm{mV} / \mathrm{s}$.

Figure 5: Cyclic voltammograms of $\mathrm{Cp}_{2} \mathrm{TiCl}_{2}\left(2.10^{-3} \mathrm{M}\right)$ in $\mathrm{THF} / n \mathrm{Bu}_{4} \mathrm{NBF}_{4}(0.3 \mathrm{M})$, at a glassy carbon electrode (1 $\mathrm{mm}$ in diameter), in the absence (solid line) and the presence of phenylacetylene: $2.10^{-3} \mathrm{M}$ (dashed line); $4.10^{-3} \mathrm{M}$ (dotted line); $6.10^{-3} \mathrm{M}$ (dash dotted line). Scan rate: $50 \mathrm{mV} / \mathrm{s}$. 
Scheme 1.

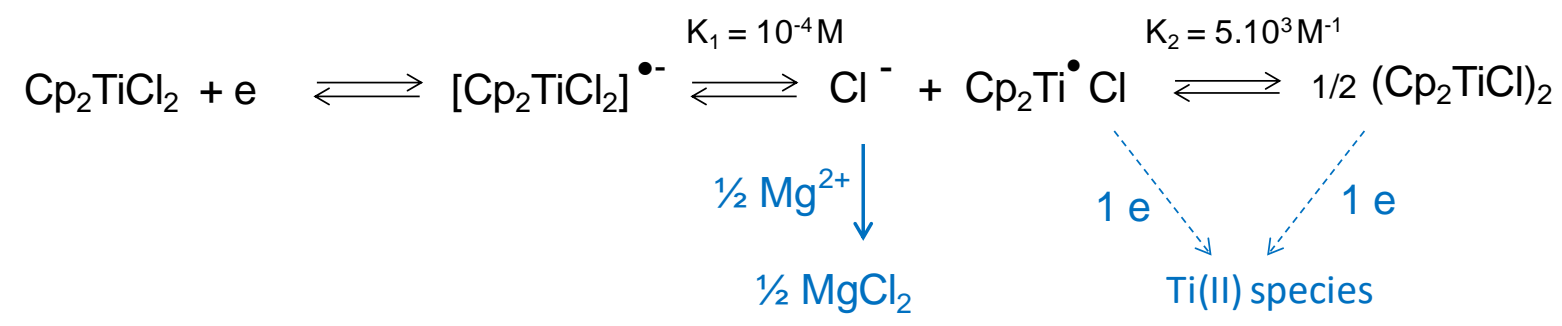

Fig. 1.

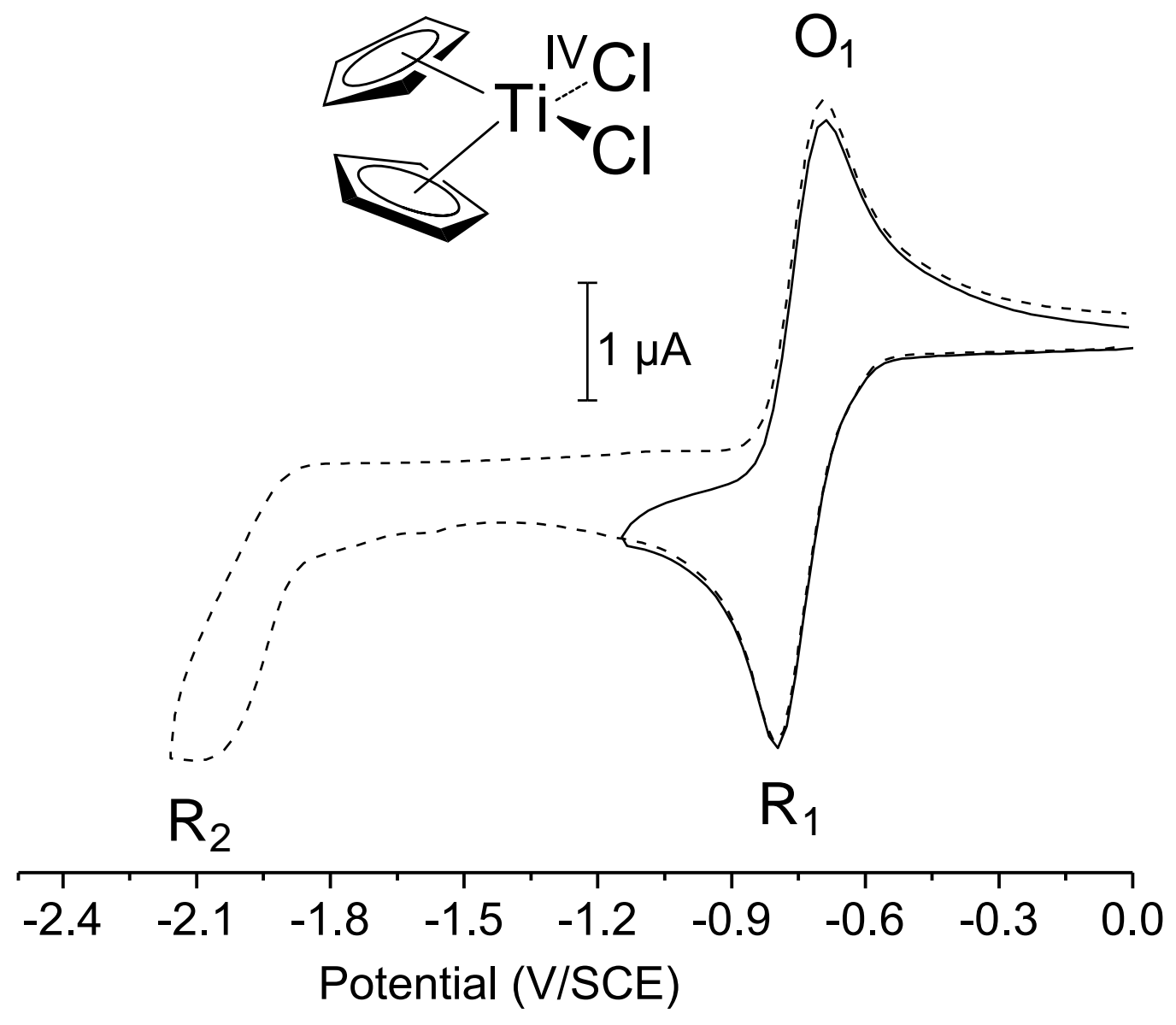


Fig. 2.

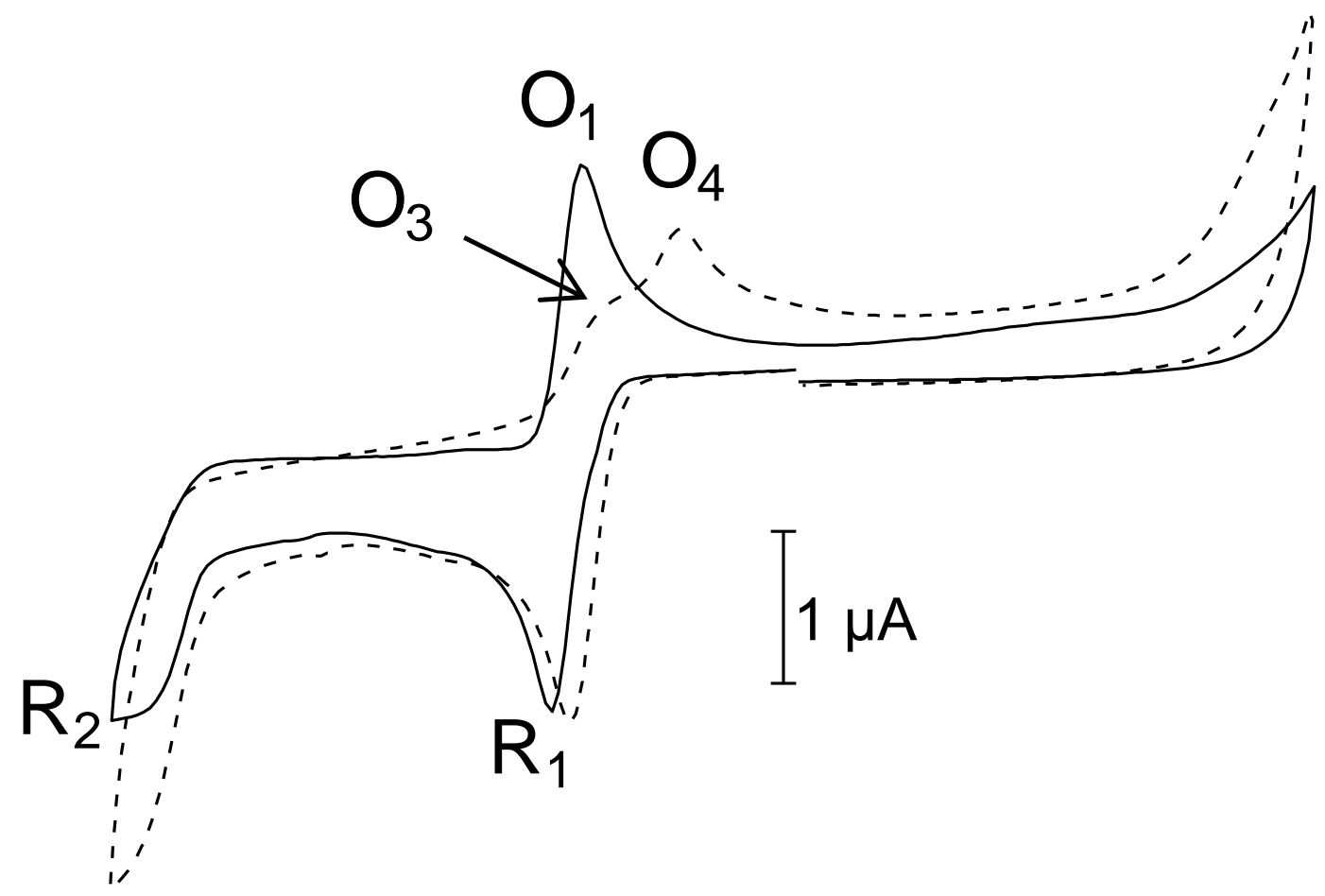

$\begin{array}{llllllllll}-2.5 & -2.0 & -1.5 & -1.0 & -0.5 & 0.0 & 0.5 & 1.0 & 1.5 & 2.0\end{array}$

Potential (V/SCE) 
Fig. 3a.

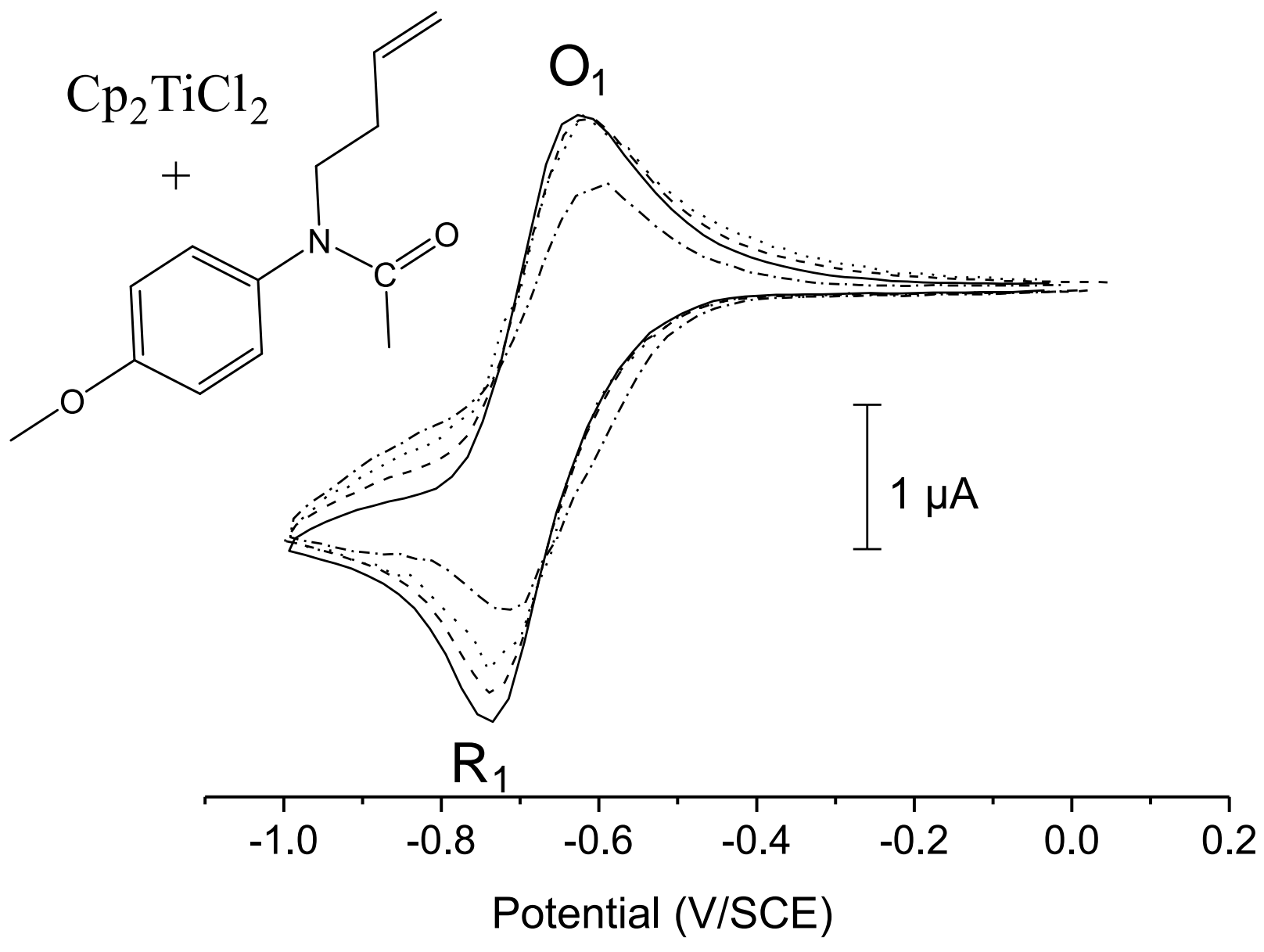


Fig. 3b.

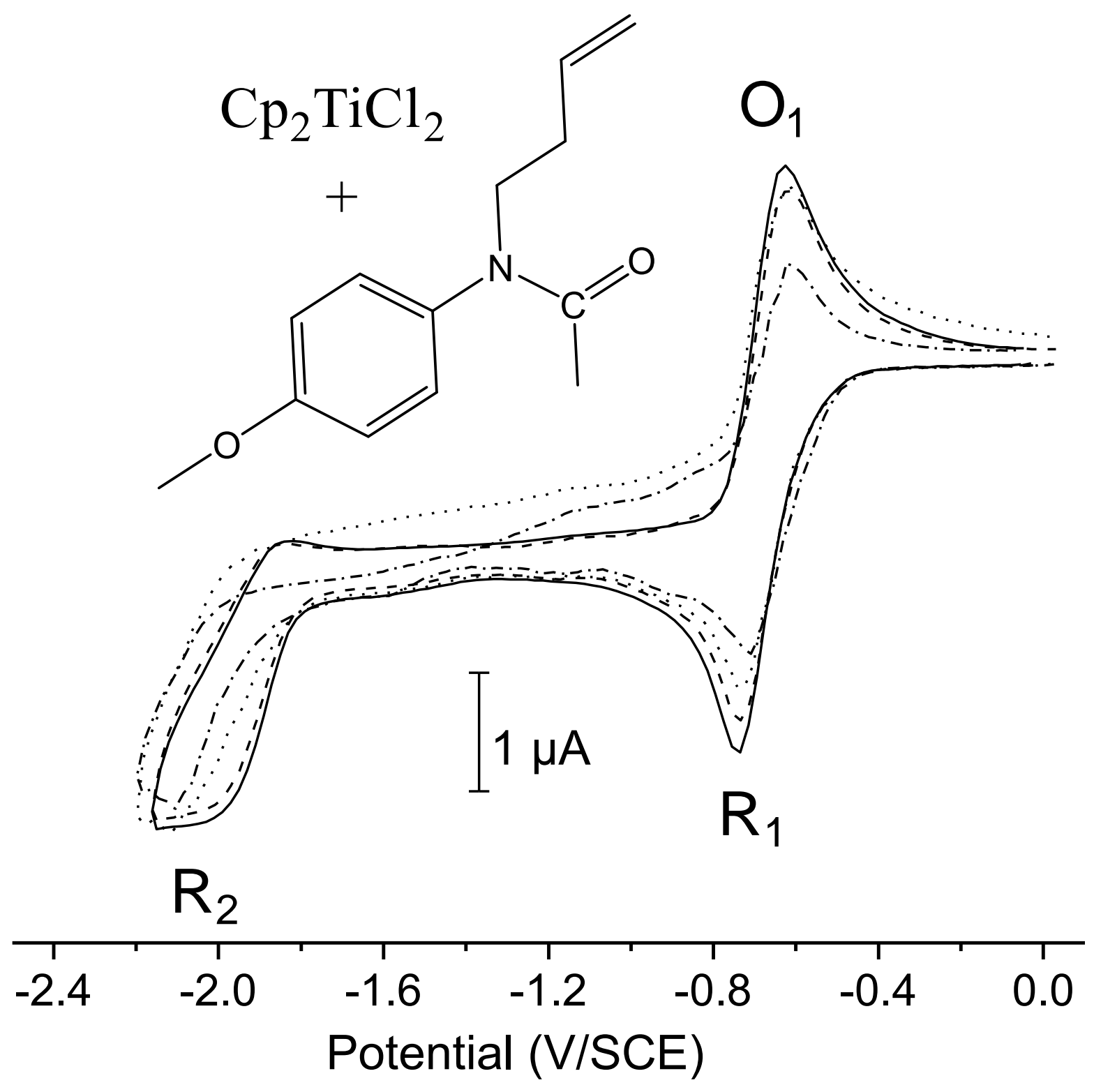


Fig. 4.

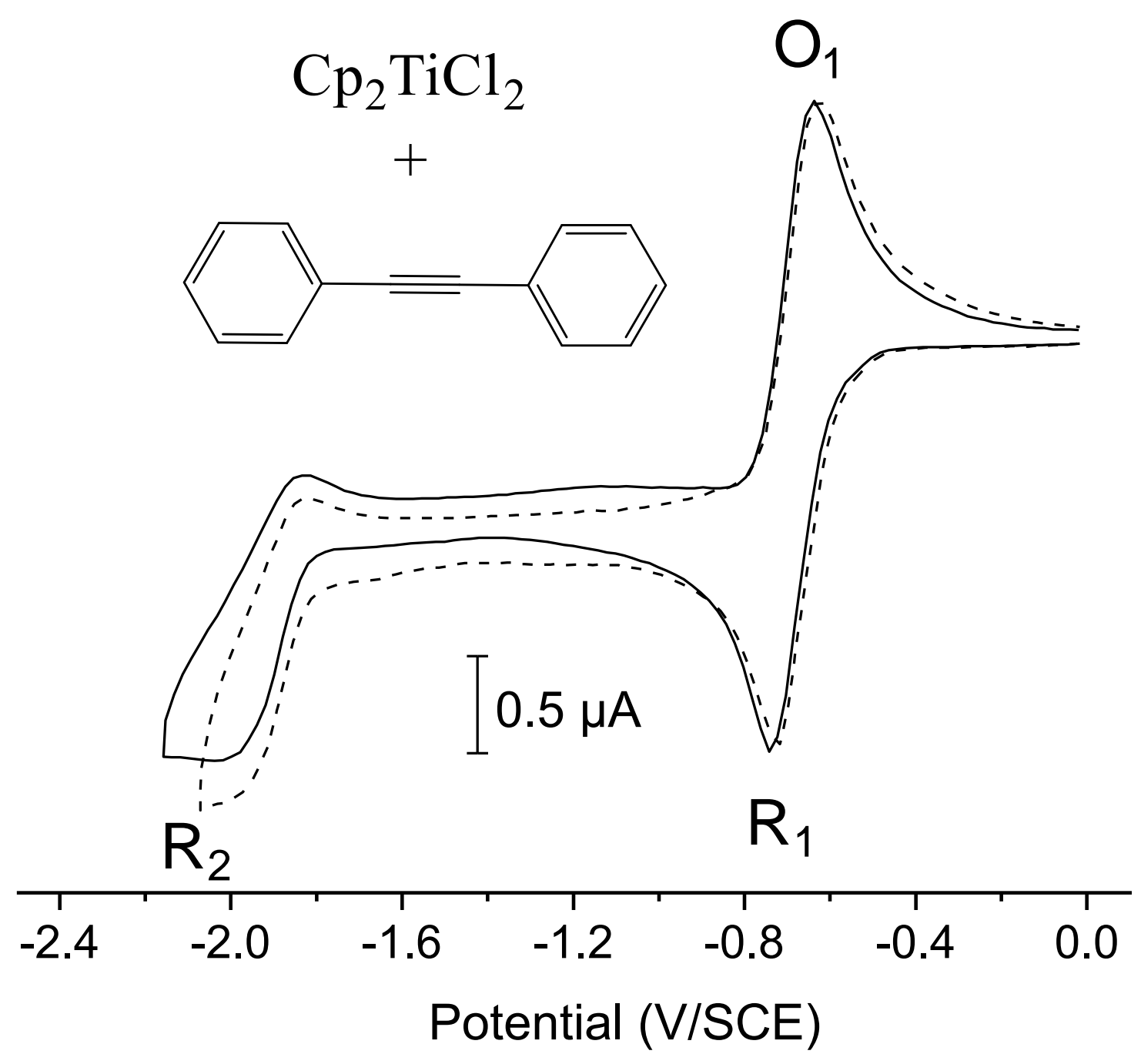


Fig. 5.

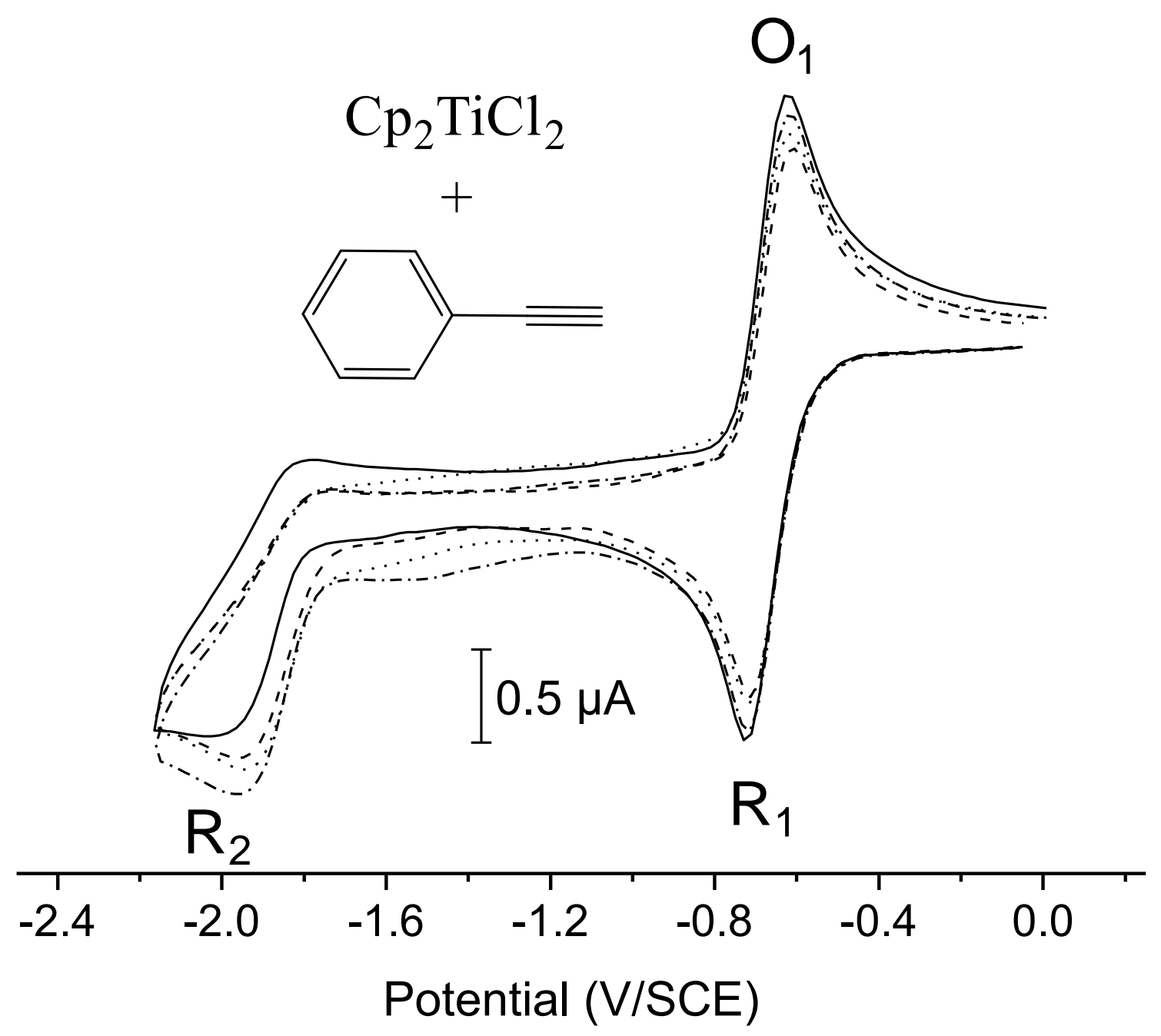

